\title{
C-25 THE SOUTHERN APENNINE THRUST BELT - FORWARD STRUCTURAL AND GEOCHEMICAL MODELLING SINCE MESSINIAN TIMES
}

\author{
S. SCIAMANNA ${ }^{12}$, R. GAMBINI ${ }^{2}$, F. MOSCA ${ }^{2}$, C. NICOLAI ${ }^{2}$, J.L. RUDKIEWICZ' and W. SASSI \\ Institut Français du Pétrole \\ 'Enterprise Oil Italiana, Via dei Due Macelli 66, 100187 Rome, Italy
}

\begin{abstract}
The Southern Apennines Thrust Belt (SATB) is a prolific petroleum province in Italy. In this work, we reconstruct its structural evolution since the Messinian and the timing of hydrocarbon generation and expulsion, integrating geological and geochemical constraints. The main exploration target in SATB is the Cretaceous part of the carbonate Apulian Platform that forms the deepest structures of the SATB below the outcropping Meso-cenozoic Allochthonous Complex. Forward structural modelling and thermal modelling have been performed along an almost $130 \mathrm{~km}$ long regional line, that crosses the Val d'Agri, where major oil discoveries are located. This forward modelling was performed with the Thrustpack code (Sassi \& Rudkiewicz, 2000).
\end{abstract}

Present-day geometry has been reconstructed integrating seismic, wells and surface data. A structural-setting involving the bottom of Apulian Platform and its base (Permian plus Basement) by means of thrusts faults deep-rooted within the crust is presented.. In order to investigate the petroleum system evolution, the timing of deformation has been defined integrating subsurface and surface data. The migrating foredeep-forebulge system of the SATB was reconstructed using geometrical, geochemical and thermal constraints. Then, the conductive thermal regime has been calibrated upon present-day temperatures and vitrinite reflectance, leading to the hydrocarbon generation and expulsion history from the source rock within the Apulian Platform. Implication for structural interpretation and Petroleum exploration are discussed.

\section{Structural and Thermal Modelling}

The aim of this paper is to demonstrate, using the Thrustpack program, that a $2 \mathrm{D}$ innovative methodology, exists to predict the timing of Hydrocarbon generation and trapping in areas affected by thrust tectonic and to validate the structural interpretation. The SATB has been chosen as the pilot geological context to test this methodology. Almost forty years of gas and petroleum exploration in Italy gave access to a large amount of subsurface data. The results presented in this paper have been achieved using mainly unpublished data available in Enterprise Oil Italiana database and subordinately from published data. The modelling has been applied along a regional line cutting through the area where the main oil discovery are located.

Regionally, two main geological members can be identified: the Allochthonous and the Apulian Platform. The former is an ensemble of Meso-Cenozoic accreted units detached from their original basement. Its complex internal geometry has been simplified for modelling purposes and approximated to an homogeneous body. The Apulian Platform is modelled as an almost continuous carbonate platform currently representing the main oil exploration target in 
the Southern Apennines. At regional scale, a constant thickness of almost $6000 \mathrm{~m}$ can be used

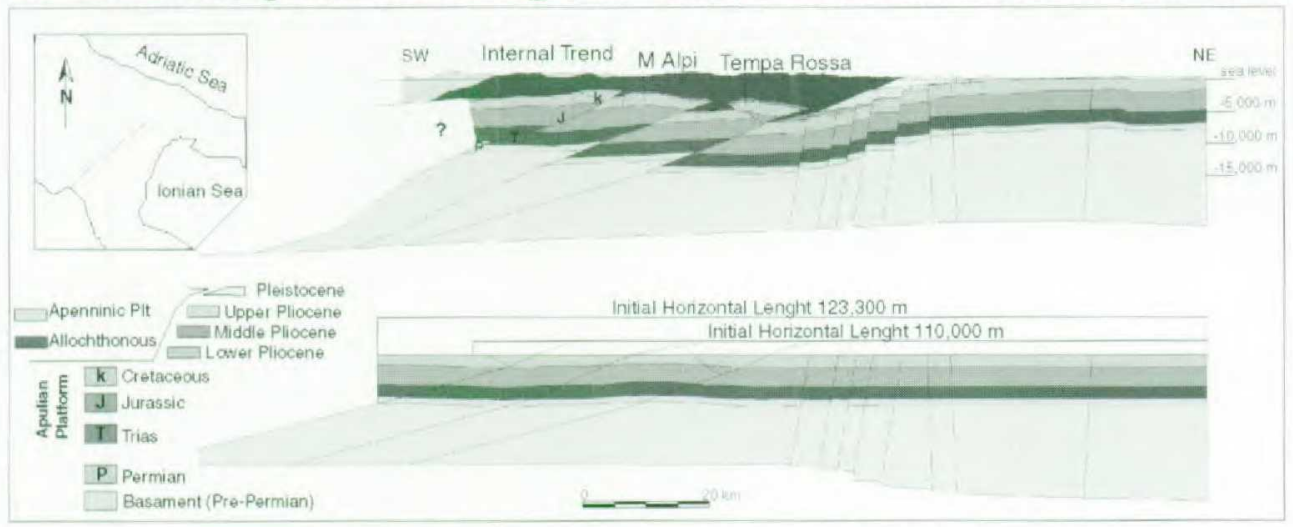

Figure 1- Present-day and restored geometries.

for the Triassic-

Miocene interval.

In addition, a

Permian interval, about $1000 \mathrm{~m}$ thick (Puglia 1) has been extrapolated regionally at the base of the Apulian Platform. Present-day

structural setting, restored Apulian Platform geometry obtained with Geosec $^{\mathrm{TM}}$ and line location are shown in Fig. 1.

The top of the Apulian Platform, imaged by seismic and wells data, is clearly dissected by thrust faults and three main structural trends can be identified from south-west toward north-east respectively: the Internal, the Monte Alpi and Tempa Rossa trends. Despite the large amount of seismic data of different quality available in the area, the magnitude of displacement along the

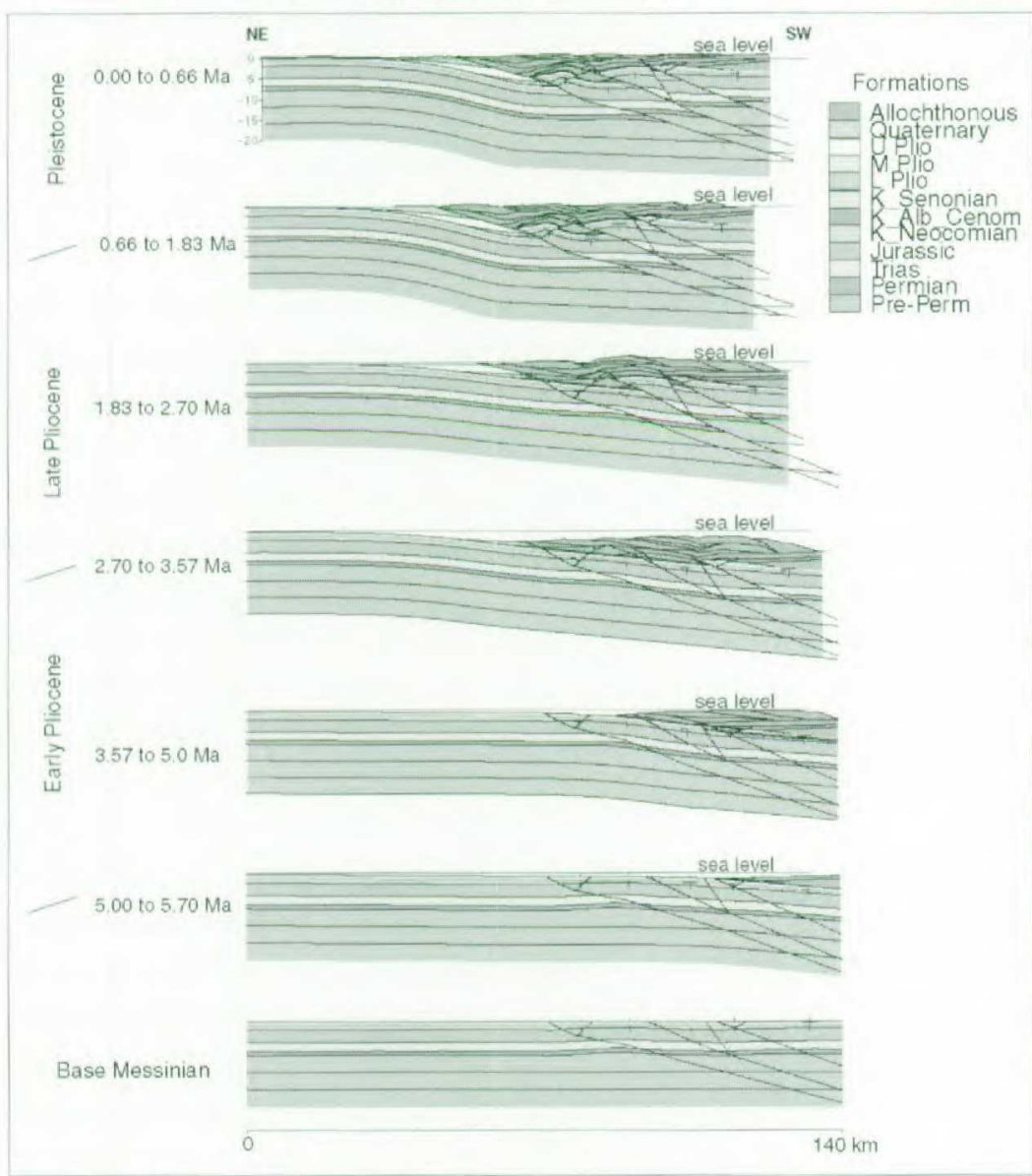

Figure 2 - Structural forward modelling. thrusts is still a matter of discussion, mainly because seismic resolution strongly decreases in the thrusts' footwall where lithological contrast disappear. The Apulian Platform bottom and its basal Permian interval seem to be always involved in thrusting. Moreover no clear evidence of any kink exists to be related with flat-ramp thrust geometry. Therefore, the bottom of the Apulian Platform and its base (Permian plus Basement) are probably involved in the deformation through deeprooted thrust faults within the crust. The basal detachment of the thrusts has been arbitrarily placed as deep as possible to avoid the geometric effect of the migrating kink within the section. This structural interpretation implies a different amount of horizontal shortening between the Apulian Platform (almost $15 \mathrm{~km}$ ) and the Allochthonous. The latter advanced almost forty kilometres to reach its present day position.

The deformation stages are shown in Fig.2 where accreted Allochthonous tectonic units override the flexuring Apulian Platform where foredeep sediments were deposited. Possible 
interplay between thrust tectonics driven by subduction processes and gravity sliding mechanisms triggered by the uplift of Apulian Platform faulted blocks were qualitatively modelled to explain the Allochthonous wedge emplacement. The timing of structural deformation was based upon the ages of the Pliocene foredeep sediments drilled on top of Apulian Platform. These are younger moving forelandward (north-eastward). Allochthonous thrust over the flexuring Apulian Platform after, or at least during the age of these deposits whilst the Apulian Platform will never be thrust before the Allochthonous emplacement.

The migrating foredeep-forebulge system of the SATB represents the keystone to perform forward modelling of the thrust belt geological evolution. In the geological literature numerous studies on foreland flexural modelling in thrust belts exist (Jordan, 1981; Lyon-Caen \& Molnar, 1983; Karner \& Watts, 1983; Royden, 1988). Most of them mainly deal with the foredeep present-day geometry or with their latest evolution stages (Waschbusch \& Royden, 1992). In order to constrain the progressive Apulian Platform flexuring through time, the Pliocene foredeep deposits directly overlying the Apulian Platform have been used to infer the position and age of different foreland onlap proximal to the corresponding peripheral bulge. The angle of each flexural profile results from a trial and error approach, during which the tectonic wedge shape through time (paleo-topography), the thrusts' geometry and relative displacement, and finally the thermal and maturity indicators acted as constraints. The flexural angle increased through time, as shown by the relation between foredeep deposit thickness and forelandward onlap shift. Our reconstruction starts at Messinian time (7.2 Ma) during evaporite formation along the internal area (south-westward). A regional uplift phase was modelled during the Late Pleistocene time assuming a constant uplift rate of $1.2 \mathrm{~km} / \mathrm{Ma}$ (Bordoni \& Valensise, 1998) during the last 0.660 Ma (Patacca \& Scandone, 1999).

The calibrated temperature and maturity indicators are shown in Fig.3. Observation points A, $\mathrm{B}$ and $\mathrm{C}$ represent respectively the Tempa Rossa, M Alpi and finally the Internal trends.

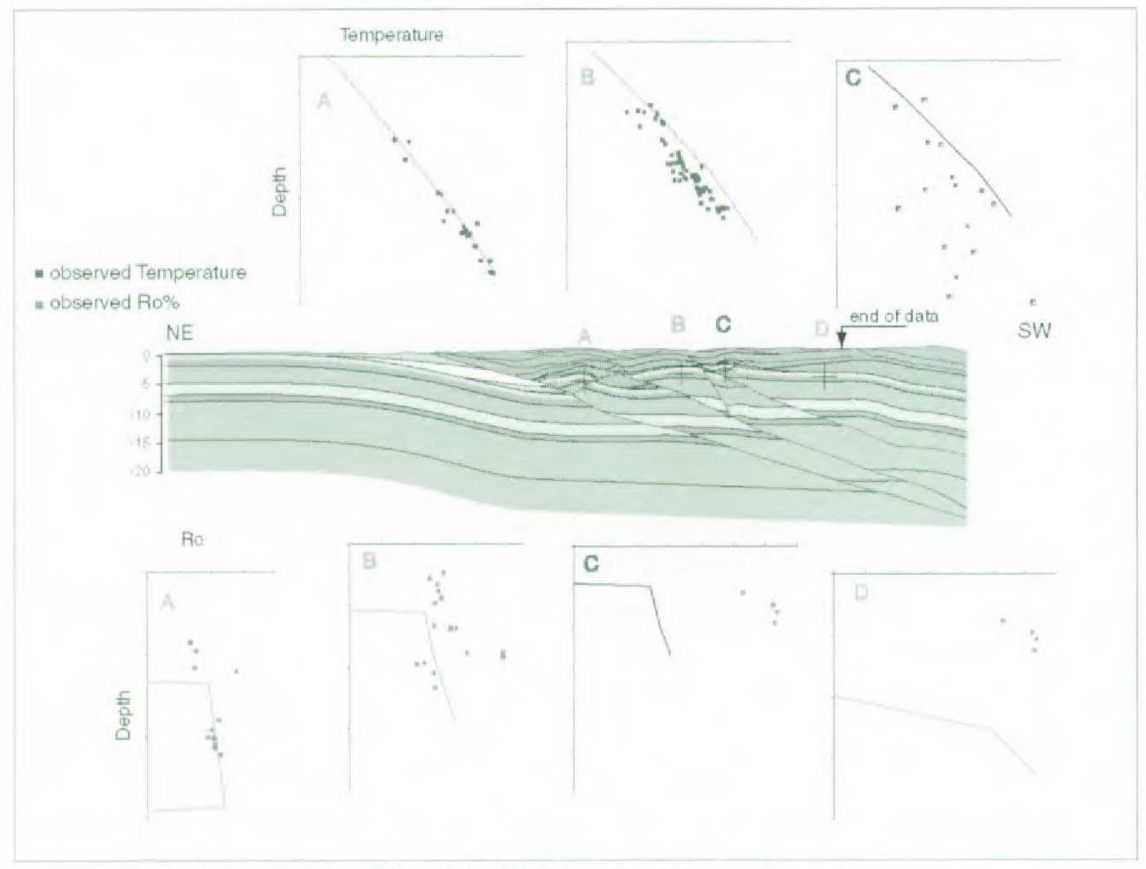

Figure 3 - Model calibration results Observation point $\mathrm{D}$ has been introduced for discussion. The calibration was achieved introducing basal heat flux distribution space-dependent but constant in time in order to fit the observed present-day temperature, maturity indicators (Ro) and surface heat flux distribution (Mongelli et al., 1989). Observed versus calculated temperatures show a good fit along the three points. In point $\mathrm{B}$ differences are in the order of $5-10{ }^{\circ} \mathrm{C}$, which is approximately the precision of the measured BHT. The maturity in the internal trend (point $\mathrm{C}$ ) cannot be calibrated without affecting the calibration in the more external trend M. Alpi. In order to calibrate the maturity on the internal trend, point $\mathrm{C}$ should undergo a burial and thermal history similar to that of the point D. 


\section{Discussion and Conclusion}

The Thrustpack forward and thermal modelling strongly suggest that the short displacement assumed between M Alpi and the Internal trends cannot explain the observed different maturity, simply because there is not enough space to introduce strong lateral thermal or burial history variations without affecting M Alpi trend too. Points D shows that in order to reach conditions through time able to allow such observed Ro range, the structural interpretation in the internal zone needs to be reviewed. The reconstructed geological evolution through time shows a feasible scenario for the Tempa Rossa and M Alpi while in the internal area two main alternatives can be proposed, implying different petroleum exploration scenarios:

1. either the structural interpretation driven by the seismic is valid and the maturity data needs to be revised to lower values; or

2. the maturity indicators collected along the internal trend are valid and suggest that M Alpi and Internal trend were originally more distant and nowadays juxtaposed by greater shortening along thrust faults, as possibly sketched in Fig.4. This schematic geometry would drastically reduce the shortening difference between the Apulian Platform and the Allochthonous.

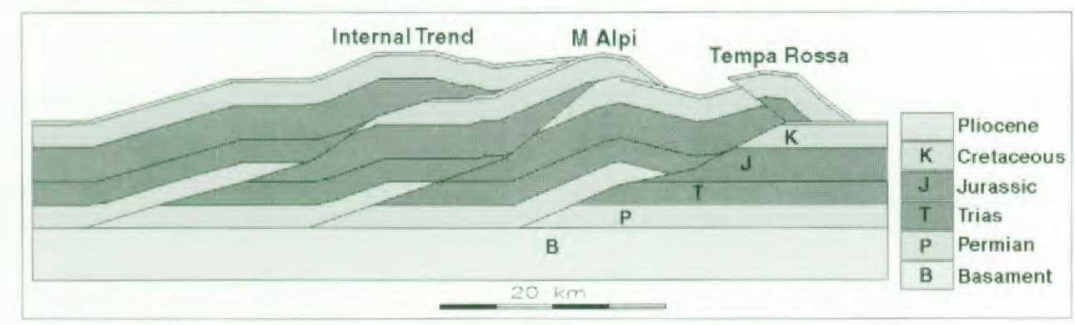

Figure 4 - Alternative structural interpretation.

Acknowledgement. We thank Scandone P. and Patacca E. for unpublished stratigraphic data and for fruitful discussions and also: Scrocca D. for geo-structural review, Shiner P. and Zucconi V for seismic interpretation. This work was supported by the European Community THERMIE Programme contract $\mathrm{OG} / 161 / 98$.

\section{Reference}

Bordoni P. \& Valensise L.(1998) - Deformation of the 125 ka marine terrace in Italy: tectonic implication. Geolog. Soc Lond., Spec. Publ., 146, 71-110.

Jordan T. E. (1981) - Thrust load and foreland basin evolution, Cretaceous, Western United States. AAPG Bull., 65, 12, 2506-2520.

Karner G.D. \& Watts A.B. (1983) - Gravity anomalies and flexure of lithosphere at Mountain Ranges. $J$. Geo. Res., 88, B10, 10449-10477.

Lyon-Caen H. \& Molnar P.(1983) - Constrains on the structure of the Himalaya from an analysis of gravity anomalies and flexure model of lithosphere. J. Geo. Res., 88, B10, 8171-8191.

Mongrelli F., Zito G., Ciaranfi \& Pieri P. (1989) - Interpretation of heat flow density of Apennine chain, Italy. Tectonophysics, 164, 267-280.

Patacca E. \& Scandone P.(1999) - -Late thrust propagation and sedimentary response in the thrust beltforedeep system of the Southern Apennines (Plio-Pleistocene. In: Vai G.B. \& Martinil.P (eds)Anatomy of a Mountain: the Apennines and adjacent Mediterranean Basin. Chapman \& Hall. London, in press.

Rudkiewicz J.L., Sassi W., Divies R. (1998) Composition of generated and expelled hydrocarbons in thrustbelts: methodology and practical examples. Proceedings of the $6^{\text {th }}$. Alago Conference. Caracas.

Royden L. (1988) - Flexural behaviour of the continental lithosphere in Italy: constrains imposed by gravity and deflection data. J. Geo. Res., 93, B7, 7747-7766.

Washbusch P.J. \& Royden L.(1992) - Spatial and temporal evolution of foredeep basin: lateral strength variations and inelastic yielding in continental lithosphere. Basin Res., 4, 179-196. 